\title{
H1N1 IN PREGNANCY
}

\author{
Spandana Bhavani ${ }^{1}$, Kavitha Naragoni², Avinash Gade ${ }^{3}$
}

${ }_{1}^{1}$ Registrar, Department of Obstetrics and Gynaecology, Krishna Institute of Medical Sciences, Kondapur, Hyderabad. ${ }^{2}$ Consultant, Department of Obstetrics and Gynaecology, Krishna Institute of Medical Sciences, Kondapur, Hyderabad. ${ }^{3}$ Consultant, Department of Pulmonology, Krishna Institute of Medical Sciences, Kondapur, Hyderabad.

HOW TO CITE THIS ARTICLE: Bhavani S, Naragoni K, Gade A. H1N1 in pregnancy. J. Evolution Med. Dent. Sci. 2017;6(75):54135414, DOI: 10.14260/Jemds/2017/1173

\section{PRESENTATION OF CASE}

A 30-year-old with $\mathrm{G}_{2} \mathrm{P}_{1} \mathrm{~L}_{1}$ of gestational age 28 weeks +4 days with history of high-grade fever, cold and cough since 1 week was referred with shortness of breath, fever and falling oxygen saturations for further management.

\section{CLINICAL DIAGNOSIS}

She was previously treated with oral antibiotics, Azithromycin and Amoxicillin and Clavulanic acid. Antenatal and postnatal period of her first pregnancy was uneventful. She had a normal vaginal delivery, has 5-year-old daughter who is alive and healthy. No other medical co-morbids.

At admission, patient was febrile and tachypnoeic with oxygen saturation of $91 \%$ with oxygen support. Examination showed bilateral crepitations. ABG (arterial blood gas) revealed raised lactate $(2.3 \mathrm{mmol} / \mathrm{L})$, respiratory alkalosis and hypoxia. Chest x-ray displayed bilateral lower zone consolidation. Sputum swab for gram stain and culture and sensitivity sent.

Patient was started on antibiotics Cefoperazone and Sulbactam, Clarithromycin, Chemoprophylaxis with Oseltamivir; Levosalbutamol and Budesonide nebulisation.

In view of falling saturations and hypoxia on $A B G$, patient was intubated. $A B G$ done 2 hours after intubation showed metabolic and respiratory acidosis, hypoxia and improvement in lactate $(1.0 \mathrm{mmol} / \mathrm{L})$.

On Day 2 of hospital stay, patient was afebrile. Obstetric ultrasound showed single live intrauterine foetus corresponding to 28 weeks gestational age with AFI of $7 \mathrm{~cm}$; estimated foetal weight of $1.69 \mathrm{~kg}$, normal foetal Doppler velocimetry. Patient had elevated blood pressure and started on antihypertensive, Labetalol. Two doses of steroids was covered for foetal lung maturity. Throat swab revealed H1N1 infection.

The possible complication of Caesarean delivery of the foetus was explained to the patient's family members and was deferred in view of maternal morbidity.

On Day 7 of hospital stay, patient had sudden desaturation $\mathrm{Sp02}$ of $80 \%$, excessive sweating and temperature of $102 \mathrm{degF}$.

Financial or Other, Competing Interest: None.

Submission 27-07-2017, Peer Review 06-09-2017,

Acceptance 12-09-2017, Published 18-09-2017.

Corresponding Author:

Spandana Bhavani

Flat 19143, Tower-19,

Prestige Bella Vista Apartments,

lyyappanthangal- 600056.

E-mail: bhavanispandana@gmail.com

DOI: $10.14260 /$ jemds/2017/1173

\section{(c) (i) $\Theta($}

Complete blood picture showed WBC count of 21,000 cells/mcL. ET (Endotracheal tube wash) and blood culture and sensitivity were sent. ET culture and sensitivity report showed Acinetobacter growth. Patient was started on Meropenem.

On Day 10 of hospital stay, patient's condition started to improve. No further temperature spikes. WBC count on declining trend. Same treatment continued. USG growth showed severe oligohydramnios AFI $2.1 \mathrm{~cm}$, normal foetal Doppler velocimetry. Foetal risks including sudden IUD were explained to the family members. In view of maternal risks, caesarean section was once again deferred. Treatment of oligohydramnios with hydration therapy was started. Antepartum foetal surveillance with amniotic fluid index measurement and Obstetric ultrasound with foetal Doppler velocimetry was done twice a week.

On Day 12 of hospital stay, patient had no further temperature spikes. Patient was weaned off ventilator and extubated the next day.

Obstetric USG showed improvement of AFI to normal value with normal foetal Doppler velocimetry.

Patient had no further respiratory issues or no temperature, hence discharged.

This patient continued to attend regular Antenatal checkups till term and delivered by spontaneous vaginal delivery at 37 weeks of gestation. She delivered a healthy baby of weight $2.65 \mathrm{~kg}$. No intrapartum or postpartum complications.

\section{PATHOLOGICAL DISCUSSION}

An outbreak of H1N1 influenza A virus infection was detected in Mexico in March 2009.(1) In June 2009, the World Health Organisation (WHO) declared pandemic alert to the level of widespread community transmission on at least two continents. ${ }^{(2)}$ The pandemic was declared to be over in August 2010.(3) The mode of transmission of influenza viruses is through sneezing and coughing via large-particle droplets.(4) In addition to respiratory secretions, other bodily fluids have also been known to be potentially infectious.(5) The estimated median incubation period was approximately 1.5 to 3 days.(6)

Clinical manifestations include fever, cough, rhinorrhoea, sore throat, headache, shortness of breath and myalgia.(7)

In the United States an increased rate of obstetrical complications, hospitalisation and maternal mortality was observed compared with the general population, particularly during the second and third trimesters. $(7,8)$

The increased severity of influenza in pregnant women is thought to be related to normal physiologic changes and decreased immunity that occurs during pregnancy. Pregnant women were more frequently hospitalised for cardiopulmonary issues and for acute respiratory illness. Nearly, one-third of the pregnant women with confirmed H1N1 virus infection have been hospitalised. Most of them 
had severe respiratory with intensive care unit admission or mechanical ventilation, and a rate for maternal death of $25 \%$. The foetal effects of influenza have not been well studied. Transplacental transmission of influenza virus appears to be rare.(9)

\section{DISCUSSION OF MANAGEMENT}

Antiviral prophylaxis is advised in pregnant and postpartum women with significant exposures up to two weeks after delivery.

No adverse events have been associated with oseltamivir or zanamivir among women who received these drugs during pregnancy or among infants exposed in utero.(10,11) The doses of influenza antiviral medications recommended for chemoprophylaxis of influenza A and B are(12) Zanamivir 10 mg (2 inhalations) once daily for up to 10 days and oral Oseltamivir $75 \mathrm{mg}$ once daily for up to 10 days (therapeutic dose being $75 \mathrm{mg}$ twice daily for 10 days). Symptomatic therapy for cough, rhinorrhoea, sore throat, headache and myalgia can be advised.

Antibiotics are indicated only for secondary bacterial complications of acute influenza, such as bacterial pneumonia, otitis media or sinusitis. Foetal Assessment techniques include:(13) Foetal movement counting, Contraction stress test, Non-stress test, Biophysical profile, Amniotic fluid volume, Doppler velocimetry-Foetal Umbilical artery and Middle cerebral artery. Foetal testing should be performed periodically until delivery if the clinical condition and foetal risk that prompted foetal surveillance continues to exist. Testing is typically performed weekly, but the frequency may be increased if there is a change in pregnancy status. Since 2004, the US CDC Advisory Committee on Immunisation Practices has recommended that all women who are pregnant or will be pregnant during influenza season should receive inactivated influenza vaccine, regardless of trimester.(14) Pregnant women should not receive a liveattenuated influenza vaccine, which is available as an intranasal spray. In conclusion, H1N1 infection in pregnancy has high maternal morbidity and mortality, hence immediate and aggressive treatment is advised for better maternal and foetal outcome.

\section{FINAL DIAGNOSIS}

$\mathrm{G}_{2} \mathrm{P}_{1} \mathrm{~L}_{1}$ of gestational age 28 weeks with $\mathrm{H} 1 \mathrm{~N} 1$ Influenza.

\section{REFERENCES}

[1] Centers for Disease Control and Prevention (CDC). Outbreak of swine-origin influenza A (H1N1) virus infection-mexico, March-April 2009. MMWR Morb Mortal Wkly Rep 2009;58(17):467-70.
[2] Chan M. World Health Organization. World now at the start of 2009 influenza pandemic.

[3] World Health Organization. In focus: H1N1 now in the post-pandemic period. August 10, 2010. http://www.who.int/csr/disease/swineflu/en/index. html (Accessed on September 21, 2010).

[4] United States Centers for Disease Control and Prevention. Interim guidance on infection control measures for 2009 H1N1 influenza in healthcare settings, including protection of healthcare personnel. http://www.cdc.gov/h1n1flu/guidelines_infection_co ntrol.htm (Accessed on October 14, 2011).

[5] Yoo SJ, Moon SJ, Kuak EY, et al. Frequent detection of pandemic (H1N1) 2009 virus in stools of hospitalized patients. J Clin Microbiol 2010;48(6):2314-5.

[6] Writing Committee of the WHO Consultation on Clinical Aspects of Pandemic (H1N1) 2009 Influenza. Clinical aspects of pandemic 2009 influenza A (H1N1) virus infection. N Engl J Med 2010;362:1708-19.

[7] Jamieson DJ, Honein MA, Rasmussen SA, et al. H1N1 2009 influenza virus infection during pregnancy in the USA. Lancet 2009;374(9688):451-8.

[8] Centers for Disease Control and Prevention (CDC). Maternal and infant outcomes among severely ill pregnant and postpartum women with 2009 pandemic influenza A (H1N1)-United States, April 2009-August 2010. MMWR Morb Mortal Wkly Rep 2011;60(35):1193-6.

[9] Irving WL, James DK, Stephenson T, et al. Influenza virus infection in the second and third trimesters of pregnancy: a clinical and seroepidemiological study. BJOG 2000;107(10):1282-9.

[10] Ward P, Small I, Smith J, et al. Oseltamivir (Tamiflu) and its potential for use in the event of an influenza pandemic. J Antimicrob Chemother 2005;55(Suppl 1):i5-i21.

[11] Freund B, Gravenstein S, Elliott M, et al. Zanamivir: a review of clinical safety. Drug Saf 1999;21(4):267-81.

[12] Fiore AE, Fry A, Shay D, et al. Antiviral agents for the treatment and chemoprophylaxis of influenzarecommendations of the advisory committee on immunization practices (ACIP). MMWR Recomm Rep 2011;60(1):1-24.

[13] Practice bulletin no. 145: antepartum fetal surveillance. Obstet Gynecol 2014;124(1):182-92.

[14] Grohskopf LA, Sokolow LZ, Broder KR, et al. Prevention and control of seasonal influenza with vaccines recommendations of the advisory committee on immunization practices-united states, 2016-17 influenza season. MMWR Recomm Rep 2016;65(5):154. 